\title{
IMPLEMENTASI E-TICKETING UJI KELAYAKAN KENDARAAN BERMOTOR UNTUK MENINGKATKAN PELAYANAN PUBLIK
}

\author{
Neng Senja Nekida ${ }^{1}$, Rizal Amegia Saputra ${ }^{2}$, Lis Saumi Ramdhani ${ }^{3}$, Taufik Hidayatulloh ${ }^{4}$ \\ ${ }^{1}$ STMIK Nusa Mandiri Sukabumi \\ e-mail: nengsenja@gmail.com \\ ${ }^{2,3} \mathrm{AMIK}$ BSI Sukabumi \\ e-mail: rizal.rga@bsi.ac.id, lis.lud@bsi.ac.id \\ ${ }^{4}$ AMIK BSI Jakarta \\ e-mail: taufik.tho@bsi.ac.id
}

\begin{abstract}
Abstrak
Pemerintah Tradisional yang identik dengan paper-based administration mulai ditinggalkan, karena sistem tersebut menjadikan pelayanan kurang efektif dan efisien. Transformasi traditional government menjadi electronic government (e-Government) menjadi salah satu isu kebijakan publik yang hangat dibicarakan saat ini, karena hampir semua perusahaan dan instansi sudah beralih ke sistem yang komputerisasi. Salah satunya pengelolaan layanan uji kendaraan bermotor, dalam proses layanannya banyak permasalahan terutama pada pelayanan pendaftaran pengajuan uji KIR yang masih manual, itu mengakibatkan penumpukan antrian karena dibatasinya kuota uji kendaraan, banyak pemilik kendaraan yang tidak mendapatkan informasi berapa jumlah antrian yang sudah masuk, hal ini menjadi permasalahan yang harus segera diperbaiki agar pelayanan publik semakin membaik. Model pendekatan yang digunakan dalam pengembangan sistem ini yaitu model waterfall, dengan menggunakan bahasa pemrograman PHP (Hypertext Prepocessor) dan databasenya menggunakan MySQL. Tujuan penelitian yaitu menerapkan sistem informasi E-Ticketing untuk memberikan kemudahan dalam mengelola informasi dengan cepat, tepat dan akurat serta memberikan kemudahan kepada pemilik kendaraan untuk melakukan pendaftaran uji kendaraan tanpa harus datang langsung ke Dinas Perhubungan Kota Sukabumi

Kata kunci : E-Ticketing, Pendaftaran, Uji Kendaraan Bermotor
\end{abstract}

\section{Abstract}

The traditional government which is identical with paper-based administration is being abandoned, because the system makes services less effective and efficient. Traditional government to electronic government (e-Government) transformation has become one of the most publicly discussed policy issues today, because almost all companies and agencies have switched to a computerized system. One of them is the management of motorized vehicle testing services, in the service process there are many problems, especially in the registration service for KIR test applications that are still manual, it results in a queue buildup due to the limitation of vehicle test quota, many vehicle owners who do not get information on how many queues have been entered, this becomes a problem that must be corrected immediately so that public services improve. The approach model used in the development of this system is the waterfall model, using the PHP (Hypertext Prepocessor) programming language and its database using MySQL. The research objective is to implement an E-Ticketing information system to provide convenience in managing information quickly, precisely and accurately and to provide convenience to vehicle owners to register vehicle tests without having to come directly to the Transportation Office of Sukabumi City

Keywords: E-Ticketing, Registration, Motorized Vehicle Test

\section{Pendahuluan}

Suatu instansi pemerintahan pada saat ini menghadapi tekanan dari berbagai pihak untuk meningkatkan kualitas pelayanan publik (Holle, 2011). Peningkatan pelayanan publik (public service) harus mendapatkan perhatian utama dari suatu instasi pemerintah, karena pelayanan publik merupakan hak-hak sosial 
dasar dari masyarakat (social rihgts) ataupun (fundamental rights) (Hadjon, Djamiati, Addink, \& Berge, 2011).

Pemerintah Tradisional (traditional government) yang identik dengan paperbased administration mulai ditinggalkan, karena sistem tersebut menjadikan pelayanan kurang efektif dan efisien. Transformasi traditional government menjadi electronic government (eGovernment) menjadi salah satu isu kebijakan publik yang hangat dibicarakan saat ini, karena hampir semua perusahaan dan instansi sudah beralih ke sistem yang komputerisasi (Holle, 2011)

Dinas Perhubungan (Dishub) Kota Sukabumi memiliki berbagai Unit Pelayanan Teknis (UPT), salah satunya yaitu UPT Pengujian Kendaraan Bermotor (KIR), UPT ini merupakan suatu instansi pemerintah yang mengelola layanan uji kendaraan bermotor, dalam proses layanannya banyak permasalahan terutama pada pelayanan pendaftaran pengajuan uji KIR yang masih manual, itu mengakibatkan penumpukan antrian karena dibatasinya kuota uji kendaraan perhari yaitu 25 kendaraan, banyak pemilik kendaraan yang tidak mendapatkan informasi berapa jumlah antrian yang sudah masuk, hal ini menjadi permasalahan yang harus segera diperbaiki agar pelayanan publik UPT semakin membaik.

Berdasarkan kondisi dan permasalahan di atas maka penelitian ini bertujuan untuk mengimplementasikan sistem informasi E-Ticketing Uji kendaraan bermotor berbasis web untuk memudahkan pemilik kendaraan melakukan pendaftaran uji kendaraan bermotor.

\section{Metode Penelitian}

Penelitian yang dilakukan oleh Rosul, M dan Yudie Irawan (2014) tentang Sistem informasi pendaftaran pengujian kendaraan pada dinas perhubungan Kabupaten Pati, masih manual hal ini mengakibatkan sistem antrian kurang efektif, untuk itu sistem komputerisasi yang berbasis desktop, akan memudah kasir dalam mengelola sistem pendaftaran pengujian kendaraan agar lebih efektif dan efisien.

Penelitian oleh Syarifuddin dan Budianto (2017). Salah satu syarat angkutan umum untuk bisa beroperasi di Kota Malang adalah lulus pada uji KIR yang dilakukan oleh Dinas Perhubungan Kota Malang. Hasil dari uji KIR kelayakan angkutan masih menggunakan perhitungan manual, sedangkan banyak angkutan yang melakukan uji KIR setiap harinya. Oleh karena itu diperlukan sistem pendukung keputusan kelayakan angkutan umum berdasarkan uji KIR pada Dinas Perhubungan Kota Malang. Sistem pendukung keputusan ini, dapat menentukan nilai perhitungan terhadap semua kriteria. Sistem ini menggunakan metode Simple Additive Weighting (SAW). Pada kasus ini metode SAW dapat menentukan kelayakan angkutan berdasarkan nilai tertinggi. Dengan demikian sistem ini mampu mempersingkat proses verifikasi kelayakan angkutan umum pada Dinas Perhubungan Kota Malang, sehingga membantu penguji dalam menentukan angkutan yang layak jalan.

Dalam upaya pengumulan data, maka dilakukan tiga metode, yaitu:

1. Observasi

Metode ini dilakukan dengan cara pengamatan langsung terhadap sistem yang berjalan pada UPT Pegujian Kendaraan Bermotor Dishub Kota Sukabumi dalam pendaftaran pengujian kendaraan bermotor untuk kemudian dipelajari untuk mencari permasalahan yang ada.

2. Wawancara

Metode ini dilakukan untuk memperoleh informasi dari objek yang diteliti dalam hal ini yang menjadi objek wawancara adalah Bidang Umum dan Kepegawaian.

3. Studi Pustaka

Metode studi pustaka dilakukan dengan cara mencari data dari sumber bukubuku, makalah-makalah, e-journal, website dan lain sebagainya yang berhubungan dengan studi literatur yang berhubungan dengan $e$ commerce.

Untuk model pengembagan perangkat lunak menggunakan model waterfall.

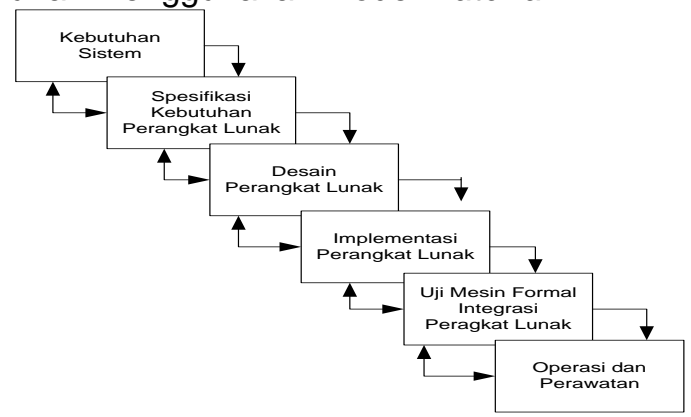

Gambar 1. Model Pengembangan Waterfall 
Sumber : Simarmata (2010:54)

Tahapan pengembangan perangkat lunak sebagai berikut:

1. Analisa Kebutuhan Software

Pada tahap ini akan digunakan apabila sistem yang nantinya akan dijalankan mempunyai kendala atau masalah sehingga bisa dianalisis terjadinya kesalahan dalam sistem yang berjalan untuk memperbaikinya sampai sistem ini berjalan dengan baik dan dapat digunakan.

2. Desain

Proses desain terbagi kedalam beberapa bagian desain yakni desain database, desain sistem dan desain interface. Pada skripsi ini software yang digunakan untuk mendesain database adalah ERD, LRS. Sedangkan software yang digunakan sebagai tool untuk merancang interface adalah Android Studio dan Dreamweaver.

3. Code Generation

Proses pembuatan coding atau pengkodean merupakan penterjemahan desain ke dalam bahasa yang bisa dikenali oleh komputer yang akan menterjemahkan permintaan user ke sebuah software dalam penelitian ini bahasa pemrograman yang digunakan adalah PHP dan HTML.

4. Testing

Proses mememukan kesalahan terhadap sistem yang telah diimplementasikan kedalam sebuah software pada penelitian ini teknik pengujian yang akan dilakukan adalah teknik blackbox testing.

5. Support

Untuk meningkatkan kualitas program antara lain dengan cara rutin melakukan maintenance terhadap program dan juga pengupdatean antivirus dan juga melakukan back up data apabila program error.

\section{Hasil dan Pembahasan}

Hasil dari penelitian ini yaitu berupa web yang terintegrasi, yang berisi pendaftaran member, pendaftaran pengujian kendaraan dilakukan secara online, jumlah pendaftaran dapat terlihat pada web yang dibuat, dan laporan hasil pengujian kendaraan dapat diperoleh dengan mudah.

\subsection{Use Case Diagram}

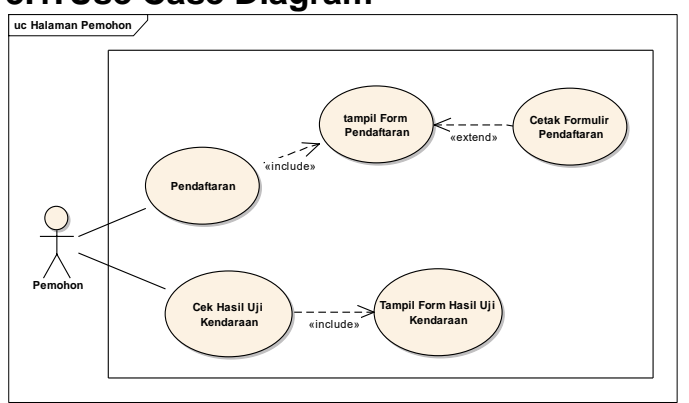

Gambar 2. Use Case Diagram Uji Kendraan Bermotor Halaman Pemohon

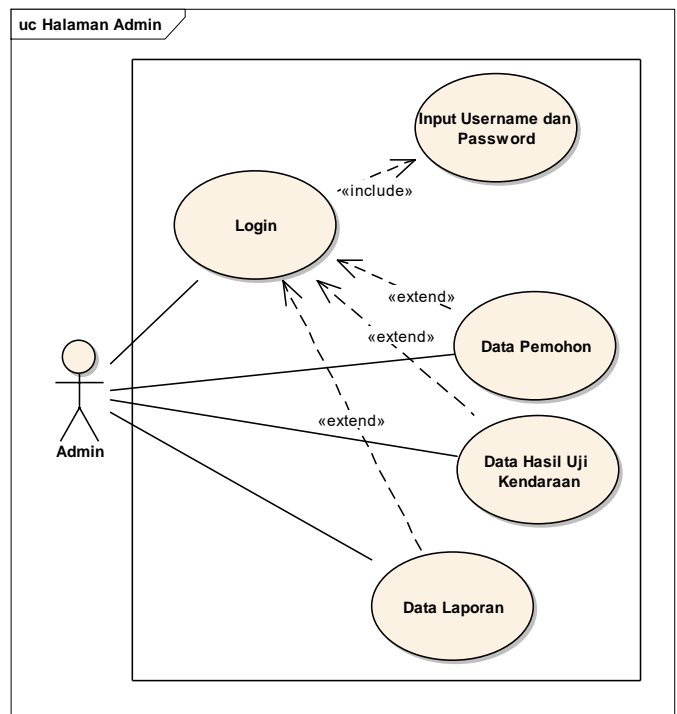

Gambar 3. Use Case Diagram Uji Kendaraan Bemotor Halaman Admin

\subsection{Entity Relationship Diagram}
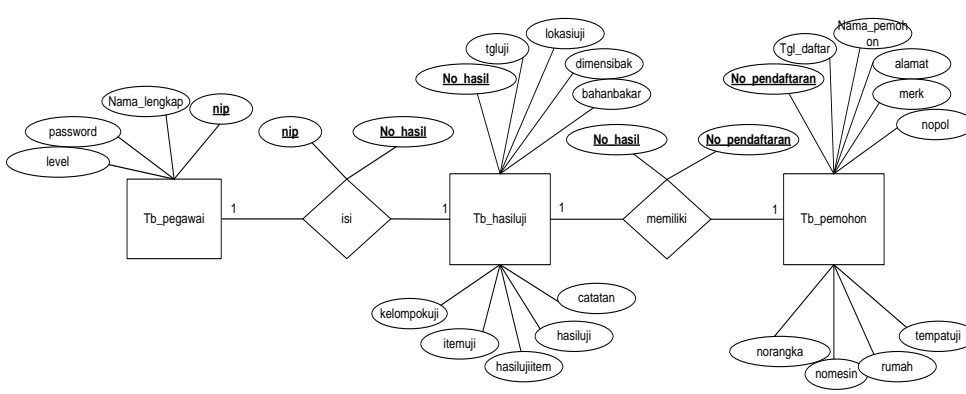

Gambar 4. Entity Relationshop Diagram

Pendaftaran Uji Kelayakan Kendaraan

\subsection{Spesifikasi File}

1. Spesifikasi File Tabel Pegawai

Nama Database : db_kir

Nama File : :Tabel Pegawai

Akronim : tb_pegawai.myd

Tipe File : File Master

Akses File : Random 


$\begin{array}{ll}\text { Panjang Record } & : 100 \text { Byte } \\ \text { Kunci Field } & \text { : nip }\end{array}$

Tabel 1. Spesifikasi File Tabel Pegawai

\begin{tabular}{|l|l|l|l|l|}
\hline No & Nama Field & Type & Size & $\begin{array}{l}\text { Keteranga } \\
\mathrm{n}\end{array}$ \\
\hline 1 & Nip & Varchar & 20 & $\begin{array}{l}\text { Primary } \\
\text { Key }\end{array}$ \\
\hline 2 & $\begin{array}{l}\text { nama_lengk } \\
\text { ap }\end{array}$ & Varchar & 20 & \\
\hline 3 & password & Varchar & 40 & \\
\hline 4 & Level & Varchar & 20 & \\
\hline
\end{tabular}

2. Spesifikasi File Tabel Pemohon

$\begin{array}{ll}\text { Nama Database } & \text { : db_kir } \\ \text { Nama File } & \text { : Tabel Pemohon } \\ \text { Akronim } & \text { : tb_pemohon.myd } \\ \text { Tipe File } & \text { : File Transaksi } \\ \text { Akses File } & \text { : Random } \\ \text { Panjang Record } & : 172 \text { Byte } \\ \text { Kunci Field } & \text { : no_pendaftaran }\end{array}$

Tabel 2. Spesifikasi File Tabel Pemohon

\begin{tabular}{|c|c|c|c|c|}
\hline No & Nama Field & Type & $\begin{array}{l}\text { Siz } \\
\text { e }\end{array}$ & $\begin{array}{l}\text { Keteran } \\
\text { gan }\end{array}$ \\
\hline 1 & $\begin{array}{l}\text { no_pendaftara } \\
\text { n }\end{array}$ & $\begin{array}{l}\text { Varcha } \\
\mathrm{r}\end{array}$ & 20 & $\begin{array}{l}\text { Primary } \\
\text { Key }\end{array}$ \\
\hline 2 & Tgl_daftar & $\begin{array}{l}\text { Varcha } \\
r\end{array}$ & 10 & \\
\hline 3 & $\begin{array}{l}\text { Nama_pemoh } \\
\text { on }\end{array}$ & $\begin{array}{l}\text { Varcha } \\
\text { r }\end{array}$ & 20 & \\
\hline 4 & alamat & Text & - & \\
\hline 5 & merk & $\begin{array}{l}\text { Varcha } \\
r\end{array}$ & 20 & \\
\hline 6 & nopol & $\begin{array}{l}\text { Varcha } \\
r\end{array}$ & 20 & \\
\hline 7 & norangka & $\begin{array}{l}\text { Varcha } \\
r\end{array}$ & 30 & \\
\hline 8 & nomesin & $\begin{array}{l}\text { Varcha } \\
r\end{array}$ & 30 & \\
\hline 9 & Rumah & int & 11 & \\
\hline 10 & tempatuji & Text & - & \\
\hline 11 & Idjenis & Int & 11 & $\begin{array}{l}\text { Foreign } \\
\text { Key }\end{array}$ \\
\hline
\end{tabular}

3. Spesifikasi File Tabel Jenis Kendaraan Nama Database : db_kir

Nama File : Tabel jenis

kendaraan

Akronim

tb_jeniskendaraan.myd

Tipe File : File Master

Akses File : Random

Panjang Record : 41 Byte

Kunci Field : idjenis

Tabel 3. Spesifikasi File Tabel Jenis Kendaraan

\begin{tabular}{|l|l|l|l|l|}
\hline No & Nama Field & Type & $\begin{array}{l}\text { Siz } \\
\text { e }\end{array}$ & $\begin{array}{l}\text { Keterang } \\
\text { an }\end{array}$ \\
\hline 1 & Idjenis & Int & 11 & $\begin{array}{l}\text { Primary } \\
\text { Key }\end{array}$ \\
\hline
\end{tabular}

\begin{tabular}{|l|l|l|l|l|}
\hline 2 & $\begin{array}{l}\text { Nama_jeniskend } \\
\text { araan }\end{array}$ & $\begin{array}{l}\text { Varch } \\
\text { ar }\end{array}$ & 30 & \\
\hline
\end{tabular}

4. Spesifikasi File Tabel Hasil Uji

Nama Database : db_kir

Nama File : :Tabel Hasil Uji

Akronim : tb_hasiluji.myd

Tipe File : File Transaksi

Akses File : Random

Panjang Record : 112 Byte

Kunci Field : no_hasil

Tabel 5.Spesifikasi File Tabel Hasil Uji

\begin{tabular}{|c|c|c|c|c|}
\hline No & $\begin{array}{l}\text { Nama } \\
\text { Field }\end{array}$ & Type & $\begin{array}{l}\text { Si } \\
\text { ze }\end{array}$ & $\begin{array}{l}\text { Ketera } \\
\text { ngan }\end{array}$ \\
\hline 1 & no hasil & int & 10 & $\begin{array}{l}\text { Primar } \\
\text { y Key }\end{array}$ \\
\hline 2 & tgl_uji & Varchar & 12 & \\
\hline 3 & Lokasiuji & Varchar & 20 & \\
\hline 4 & $\begin{array}{l}\text { Dimensi } \\
\text { bak }\end{array}$ & Varchar & 20 & \\
\hline 5 & $\begin{array}{l}\text { Bahanba } \\
\text { kar }\end{array}$ & Varchar & 20 & \\
\hline 6 & $\begin{array}{l}\text { Kelompo } \\
\text { kuji }\end{array}$ & Varchar & 10 & \\
\hline 7 & Itemuji & Text & - & \\
\hline 8 & $\begin{array}{l}\text { Hasilujiit } \\
\text { em }\end{array}$ & $\begin{array}{l}\text { enum('Lulus', } \\
\text { 'Gagal') }\end{array}$ & - & \\
\hline 9 & Hasiluji & $\begin{array}{l}\text { enum('Lulus', } \\
\text { 'Gagal') }\end{array}$ & - & \\
\hline 10 & Catatan & Text & - & \\
\hline 11 & $\begin{array}{l}\text { no_pend } \\
\text { aftaran }\end{array}$ & Varchar & 20 & $\begin{array}{l}\text { Foreig } \\
n \text { Key }\end{array}$ \\
\hline
\end{tabular}

\subsection{User Interface}

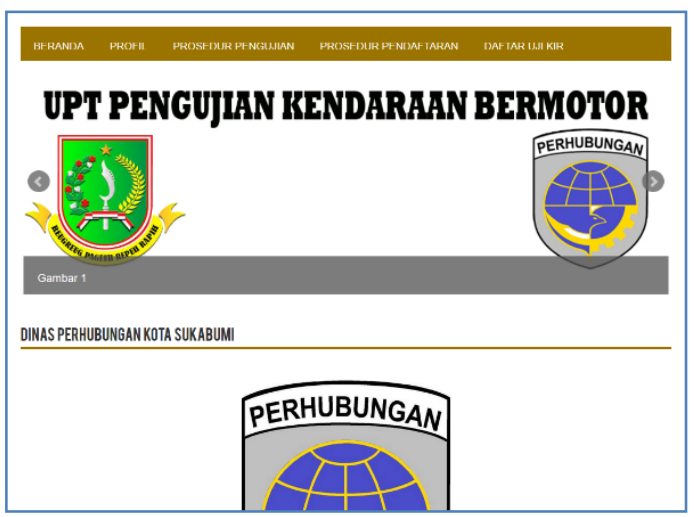

Gambar 5. Halaman Utama Konsumen 


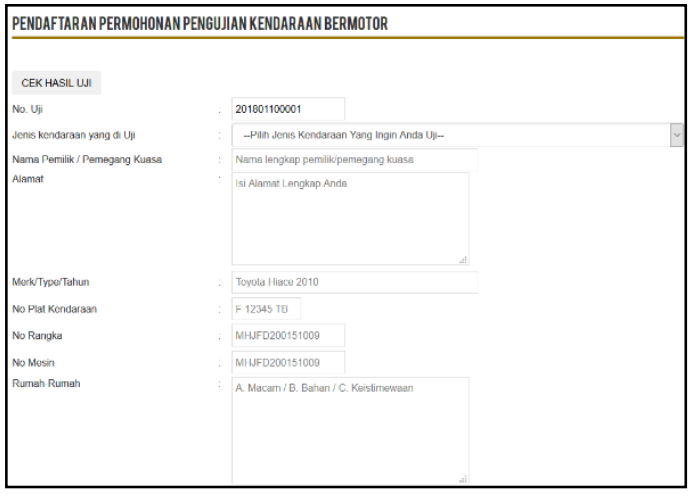

Gambar 6. Halaman Daftar Uji Kir Online

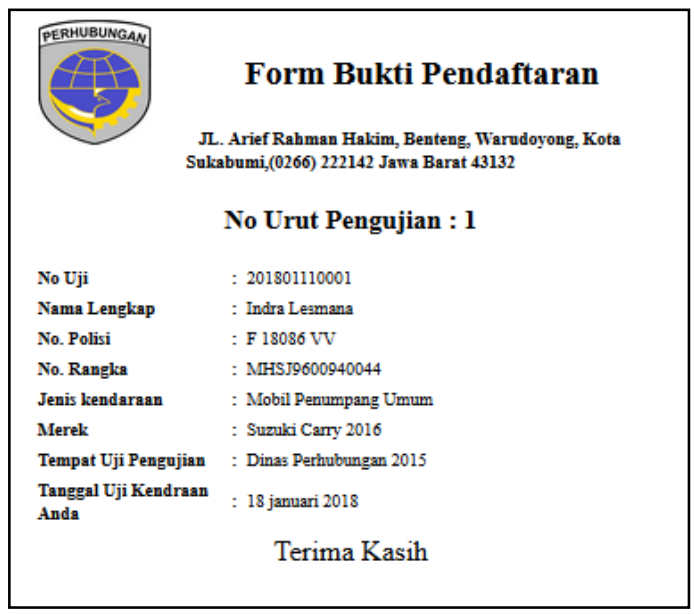

Gambar 7. Halaman Cetak Pendaftaran

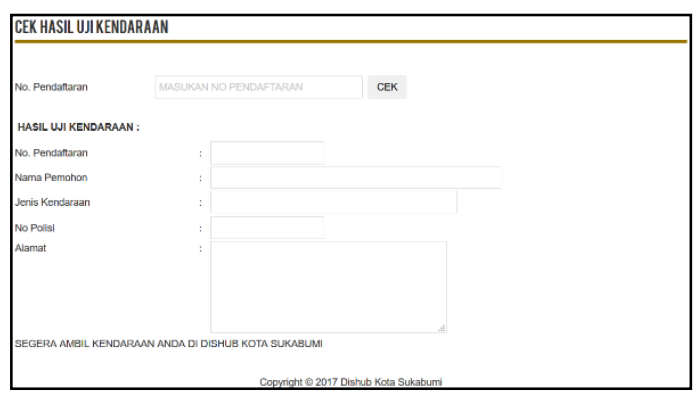

Gambar 8. Halaman Cek Hasil Uji Kendaraan

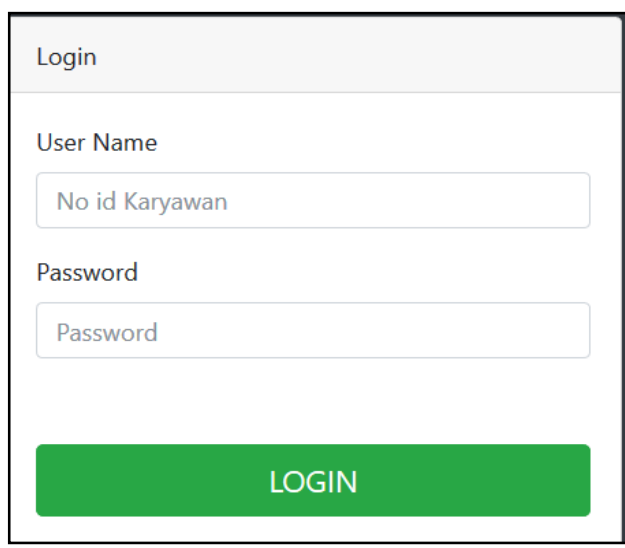

Gambar 9. Halaman Login Admin

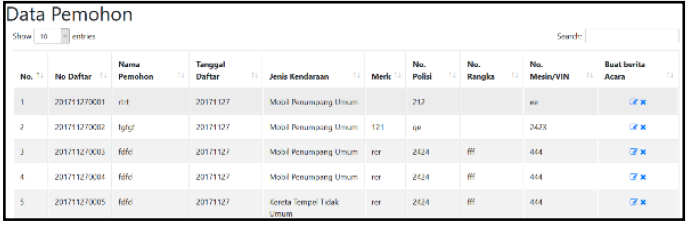

Gambar 10. Halaman Data Pemohon

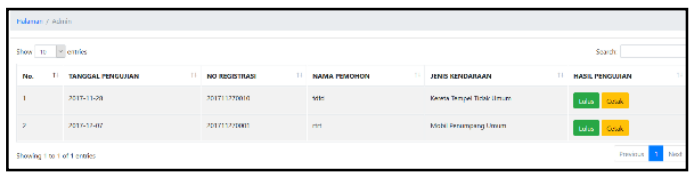

Gambar 11. Halaman Data Hasil Uji Kir

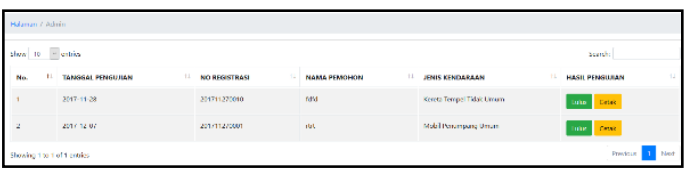

Gambar 12. Halaman Data Laporan

\section{Kesimpulan}

Dengan menerapkan e-ticketing uji kelayakan kendaraan bermotor berbasis web ini yaitu dapat meminimalisir waktu pendaftaran sehingga pemohon dapat mengetahui tanggal berapa uji kendaraannya. Selain itu pemohon dapat langsung mengetahui informasi mengenai prosedur pendaftaran uji kendaraan. Dan dalam web ini sudah ditentukan batas maksimal pendaftaran yaitu 20 kendaraan, sehingga hal ini dapat mengurangi antrian.

Berdasarkan kesimpulan diatas maka saran-saran yang dapat diberikan dalam penelitian ini yaitu: dari aspek manajerial, diperlukan pelatihan kepada beberapa orang staff sebelum sistem ini diterapkan. Dari aspek sistem, Pada periode tertentu perlu adanya pengecekan data kembali untuk menjaga kemungkinan timbulnya kelemahan sistem dan mengingat pentingnya data-data pada database maka diperlukan sistem backup untuk mencegah hal-hal yang tidak diinginkan,termasuk pemasangan antivirus.Melihat dari aspek penelitian selanjutnya diharapkan dikembangkan kearah mobile, seperti pendaftaran dapat dilakukan pada handphone dan lainnya.

\section{Referensi}

Anhar. (2010). Panduan Menguasai PHP \& MySQL secara Otodidak. Jakarta: MediaKita.

Fahrurrozi , I., \& Azhari , S. (2012). Proses Pemodelan Software Dengan 
Metode Waterfall dan Extreme. Yogyakarta: Universitas Gadjah Mada.

Hadjon, P. M., Djamiati, T. S., Addink, G. H., \& Berge, J. T. (2011). Hukum Administrasi dan Tindak Pidana Korupsi. Jogyakarta: Gadjah Mada University Press.

Holle, E. (2011). Pelayanan Publik Melalui Electronic Government: Upaya Meminimalisir Praktek Maladministrasi Dalam Meningkatan Public Service. Jurnal Sasi, 21-30.

Madcoms. (2011). Aplikasi Web Database dengan Dreamweaver dan PHP MySQL. Yogyakarta: CV Andi Offset.

Madcoms. (2012). JavaScript untuk membangun Website Profesional. Yogyakarta: CV Andi Offset.

Mulyanto, A. (2009). Sistem Informasi Konsep \& Aplikasi. . Yogyakarta: Pustaka Pelajar.

Puspitosari, A. H. (2010). Membangun Website Interaktif dengan Adobe Creative Suite 5. Yogyakarta: PT. Skripta Media Creative.

Rizky, \& Soetam. (2011). Konsep Dasar Rekayasa Perangkat Lunak. Jakarta: Prestasi Pustaka.

Rosa, A. S., \& Shalahuddin, M. (2014). Rekayasa Perangkat Lunak Terstruktur dan Berorientasi Objek. Bandung: Informatika.

Rosul, M., \& Irawan, Y. (2014). Sistem Informasi Pengujian Kendaraan Bermotor Pada Dinas Perhubungan Komunikasi Dan Informatika Kabupaten Pati. SNATIF (pp. 437444). Kudus: Universitas Muara Kudus.

Simarmata, J. (2010). Rekayasa Perangkat Lunak. Yogyakarta: Andi.

Solihin, A. (2010). MySQL 5 dari pemula hingga mahir. Jakarta: Universitas Budi Luhur.

Sukamto, \& Shalahuddin. (2013). Rekayasa Perangkat Lunak. Bandung: Informatika.

Sutabri, T. (2012). Analisis Sistem Informasi. Yogyakarta: CV Andi Offset.

Syarifuddin, M., \& Budianto, A. E. (2017). Perancangan Sistem Pendukung Keputusan Kelayakan Angkutan Umum Berdasarkan Uji Kir Pada Dinas Perhubungan Kota Malang
Dengan Metode Simple Additive Weighting (SAW). Jurnal Bimasaksi.

Tantra, R. (2012). Project Management System Information. London: Andi.

Wicaksono, A. S. (2011). Website Super Canggih dengan Plugin JQuery Terbaik. Yogyakarta: Mediakita. 